\title{
Financial Stumbling Detection Model for SMEs
}

\author{
Reham Nasser Farag ${ }^{1}$, Nashaat Al-Wakeel ${ }^{2}$ \\ Faculty of Commerce and Business Administration \\ Helwan University, Cairo, EGYPT
}

\author{
Mohamed Sameh Hassanein ${ }^{3}$ \\ Integrated Thebes Institutes for Computing and Management \\ Science, Cairo, EGYPT
}

\begin{abstract}
Access to financing is still one of the greatest obstacles facing Small and Medium Enterprises (SMEs) all over the world and prevents them from developing. Because a large percentage of these projects fail/stumble and go bankrupt, due to failures in their financial management and assets management decisions. SMEs do not only play an important role in the global economy but also it is one of the sources of social stability and an effective role in a country's economy. The previous researches indicate that BI systems are mainly applied in large enterprises, but using BI in SMEs is very rare. Thus, to enhance financial decisions, the study uses various ICT tools such as business intelligence (BI). This research develops a Financial Stumbling Detection (FSD) Model using BI that can help SMEs stakeholders in taking the proper financial decisions. The FSD model identifies the initial stumble/defect in SMEs, by using some financial ratios. And it was created relying on Design Science Research (DSR) methodology. The results of using BI in SMEs give the necessary insight into a business's financial data, and highlight if the business is heading for a financial crisis and potential failure.
\end{abstract}

Keywords-SMEs; financial statements; business intelligence (BI); DSR methodology; financial decisions

\section{INTRODUCTION}

Nowadays Small businesses are the main pillar of economic development in Egypt, and a strategic goal adopted by the Egyptian state, because of its vital role in the development and reducing unemployment, so the orientation of medium, small and micro business has become the largest engine for economies to achieve sustainable development.

In Egypt, there are nearly 2.5 million SMEs that secure about $75 \%$ of total job opportunities and represent around $99 \%$ of the non-agricultural establishments of the private sector [1], According to Fifth Economic Census (2017/2018), the number of SMEs in Egypt increased to 365.3 million establishments in the last 5 years. It represents more than $80 \%$ of the Egyptian economy's structure. In addition, SMEs are vital for promoting exports, enhancing competitiveness, and fostering innovation [2]. Egypt Vision 2030 is based on three pillars: a vibrant society, a thriving economy, and an ambitious homeland. Our economy needs a prosperous and attractive to be developed for improving investment, increasing productivity, enhancing competitiveness, and shifting from consumption to production. This is required to increase the number of small and medium enterprises, encouraging young people for entrepreneurship, stimulate innovation and creativity, to focusing on industrial and technological sectors instead of all domestic projects for commercial areas. This service is creating a kind of repetition that is not attractive because diversity is important for progress and achieving economic development.
SMEs face many challenges that lead to bankruptcy and failure. As Harraf [3] said because of the fast rate of technological transitions creates the source of uncertainty, competitive intensity, and global competition for businesses. The most important challenges SMEs faced which led to the failure of the alignment process are the lack of conscious planning, lack of strategic decision making, and sharing information [4]. Most of the problems faced SMEs because of decision making which is defined as the selection of action and method managers/organizations use to conduct the changing environment associated with speedy responsiveness [5].

Paper structure: The problem definition will be discussed in the next Section II, then in Section III the related work will presented. The research methodology will be introduced in Section IV. The development will be covered in Section V after that the evaluation will illustrated in Section VI. Last but not least the conclusion will summarize in Section VII.

\section{PROBLEM DEFINITION}

A large percentage of the failure/stumble and bankruptcy of these projects is due to a failure in their financial management and asset management decisions. Indeed, it is important to understand the decision environment for the effectiveness of the decision making, because it is considered as the source of the decision problem, decision goals, and relevant resources [6]. Therefore, businesses are increasingly and largely depending on the adequacy and accuracy of the information supply chain [7]. Although it has been recognized for its decision-making effectiveness, the study raises a concern to conduct information management in businesses. In order to increase SMEs ' resilience in times of crisis, and increase their response time to market changes, SMEs started to use various ICT tools, such as business intelligence (BI) and business process management (BPM). Despite this, previous research indicates that BI and BPM systems are mainly applied in large enterprises, while BI and BPM practices in SMEs are very low [8][9]. Researchers claim that the alignment between organizational perspectives such as strategy, structure, management processes, individual roles, and skills with technology can help to increase value in businesses, IS effectiveness, and business performance [10].

\section{RELATED WORK}

Both Pina [11] and Bosire [12] highlight the key role that BI tools play in effectively managing information in business. The successful implementation of BI tools can ensure that management benefits from improved access to up-to-date and accurate information when desired. These tools can provide 
strategic management and other stakeholders with a complete overall view of the business, thus providing benefits such as the ability to enable more reliable, faster, and more accurate decisions [13]. Therefore, organizations require assimilating and processing information for detecting the degree of effects of those changes that may help organizations to take the dynamic decision [5]. According to Adeyelure [14] organizational factors e.g. top management support, management expectations, and financial resources, are the most pertinent in the implementation of BI in SMEs. On the other hand, the prevalence of the functional organizational structure of SMEs negatively affects the implementation of the process-oriented approach [15]. SMEs reaped many benefits from the existence of BI such as efficiency. Raj et al. [16] in 2016 overcome their finds about the challenges in SMEs by developing BI tools that provide analytical data and KPIs that ensure SMEs to be managed efficiently. Raj, et al. [17] 2019 enhance his model by involving in knowledge management and discovery, helping the business to overcome its challenges. Gauzelin and Bentz [18] employ BI in SMEs to facilitate timely decision making, enable the company to meet client's needs appropriately, and lead to employees' satisfaction. Gudifinnsson and Strand [19] developed a model that enforces a change in processes and added new KPIs to ensure business efficiency. Llave [9] highlight the importance of $\mathrm{BI}$ in SMEs proposed a modified BI\&A value creation framework for SMEs with an automated data warehouse approach. Furthermore, pulled [20] develops and tests a model to act as a solution provider and to provide instrumental insights for managers helping them increase their business efficiency.

\section{Research Methodology AND CASE StUdy}

DSR Methodology was the underlining research methodology followed in the large study [21] [22], which followed in this study.

The FSD model is developed to help SMEs in their financial decisions and to address problems with strategic financial information management. An extensive literature study was conducted to drive the theoretical framework. The proposed BI framework integrated with 6 steps of the model created using DSR. Steps:

- Awareness of problem.

- Suggestion.

- Set indicators.

- Collect data and information based on indicators.

- Development.

- Evaluation.

The knowledge gained throughout accumulative stages in DSR laid the foundation for understanding the analysis of requirements for creating the suggested FSD Model.

In conjunction with DSR, case studies were used; there were eighteen case studies for eighteen different businesses. Two of them will be discussed in this paper.

\section{A. Awareness of Problem}

This has been illustrated in the introduction and problem definition sections.

\section{B. Suggestion}

This phase started with a number of interviews which were conducted with stakeholders of the businesses. These interviews result and some collected data from the findings of the literature review would be constructing the BI to articulate their requirements and establish the KPIs that are required to measure SME's financial performance. The main challenges were identified and the initial image of the desired model was set. Using this information, the business can continuously make decisions to determine if it is on the right track to meet its long-term goals or not. The initial requirements to build this model are as follows:

1) Ratios that helps in showing if the business is on right track or not are illustrated in Index $1 \& 2$ at Table I in Fig. 1 [27]:

a) Financial structure of the business: The financial structure instability is evidence of failure symptom [23], showing that if there was an efficiency or a defect in the financial structure in the business, by checking these two conditions:

i) Fixed assets $($ FFA $) \leq$ long term liab. + OE.

ii) Current assets $(\mathrm{FCA}) \leq$ short term liab. + OE.

b) Profitability Ratios: Showing the business's efficiency in obtaining the appropriate profitability in relation to the size of its Assets, Sales, Equity and Investments or not by calculating four main ratios [24][26]:

i) $\mathrm{ROS}=$ Net Income $\backslash$ Net Sales.

ii) $\mathrm{ROA}=\mathrm{Net}$ Income + Interest expense $\backslash$ average assets.

iii) $\mathrm{ROE}=\mathrm{Net}$ Income $\backslash$ average owner's equity.

iv) $\mathrm{ROI}=\mathrm{Net}$ Income $\backslash$ average investments.

c) Debt Ratios: The strength of the business's ability or inability to meet its long-term liabilities by calculating two main equations [25] [26]:

i) Debt Ratio (D.R) = total liabilities $\backslash$ total assets.

ii) Times-interest-earned Ratio (TIE.R) = income । interest expense.

d) Activity Ratios: Showing the business's efficiency/inefficiency in managing its inventory and account receivables by calculating two main equations [26]:

i) Inventory turnover $($ ITO) $=$ cost of sales $\backslash$ average inventory.

ii) Accounts Receivables turnover $(\mathrm{A} \backslash \mathrm{RTO})=$ Net sales $\backslash$ average AlR.

e) Risk Ratios: Showing the business's initial risk if existed [27].

i) Operational risk ratio (ORR): $\Delta$ Total income $\backslash \Delta$ sales.

ii) Financial risk ratio (FRR): $\Delta$ Net revenue $\backslash \Delta$ total income.

iii) Total risk ratio (TRR): $\Delta$ Net revenue $\backslash \Delta$ sales. 
f) Liquidity Ratios: Showing if the business has the efficiency in paying its current liabilities from the current assets or needed to sell from its fixed assets to pay off its liabilities, using the following four equations [26]:

i) Working capital (LWC): Current assets - Current liabilities.

ii) Current ratio (LCR): Current assets \ Current liabilities.

iii) Quick ratio (LQR): Cash + Account receivables । Current liabilities.

iv) Total coverage (LTC): Revenue before interest । Interest expense.

2) Industry ratios: An aggregate measure of industry performance. Publishers gather data from the financial statements of hundreds of firms to calculate industry averages. Often they break out the results into categories based on the asset size of the companies. These are then used as a benchmarking tool in comparing a company's performance to that of its industry. Industry ratios used in this example are according to the Financial and statistical report of the General Authority for Investment and Free Zones (GAFI), for the two fiscal years 2017, 2018[27].

\section{Set Indicators as a KPIs}

Referring to Table I:

In Index 2, highlights the equations from 1 to 17 previously defined. The key performance indicators (KPIs) for business are setting after the process the required ratios to act as a condition as follow:

- If calculated ratio increased from year to another?

- If calculated ratio greater than or equal to the industry ratios?
In index 3 the result of answering KPIs Questions of each ratio were recorded as follow:

1. True $(\sqrt{ })$ if the condition was verified.

2. False $(X)$ if the condition not verified.

The datatype format of output results is different from each other, such as integers, float, and Boolean. Thus, putting a weight for each calculated value standardized the output value. By weighting the results in Index 3, each ratio will have a weighted value. These weighted values are categorized into 3 values $(0,1$, and 2$)$ defined as follow:

Value2 $=$ If the two conditions were verified (fulfilled) $(T \backslash T)$.

Value1 $=$ Only one condition was verified (fulfilled) $(\mathrm{T} \backslash \mathrm{F})$ (F\T).

Value $0=$ None of the conditions were met $(F \mid F)$.

Index 4, the way of distribution of the weights for financial structure, liquidity, activity, and risk ratios are according to the output. The output is processed information from the weighting of any candidate SME, to be checked against the KPIs applied for all Targeted Data.

Referring to Table I:

**The weight of the current ratio in the liquidity ratios is multiplied by 2 because it has a double effect on the liquidity ratios.

* There were some special cases that must be smaller than the industry ratios and must be decreased from one year to another such as debt ratio and risk ratios, therefore interpreting the weights evaluation values is inverted [25].

TABLE I. OF FSD MODEL

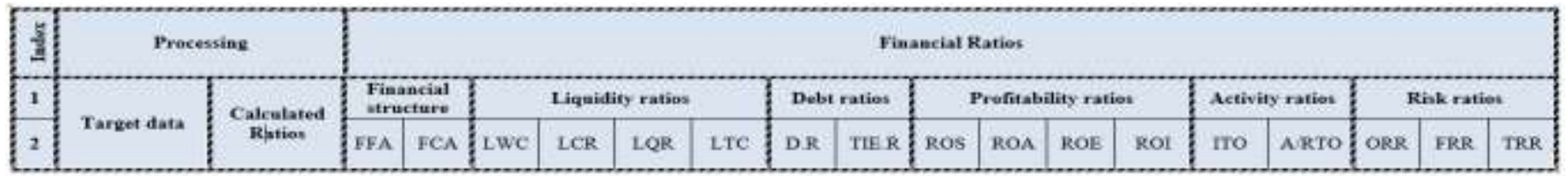

\begin{tabular}{|c|c|c|c|c|c|c|c|c|c|c|c|c|c|c|c|c|c|c|c|c|}
\hline \multirow[t]{2}{*}{3} & \multirow{2}{*}{$\begin{array}{l}\text { "Indicators } \\
\text { (KPIs) }\end{array}$} & \multirow{2}{*}{ s } & $\begin{array}{l}\text { Thom } \\
\text { jear to } \\
\text { anather }\end{array}$ & . & , & $\checkmark$ & $\checkmark$ & $\checkmark$ & $\checkmark$ & $\mathrm{x}$ & $\checkmark$ & $\checkmark$ & $\checkmark$ & $\checkmark$ & $\checkmark$ & $\checkmark$ & $\checkmark$ & $\mathbf{x}$ & $\boldsymbol{x}$ & $\mathbf{x}$ \\
\hline & & & $\begin{array}{l}\text { Indestry } \\
\text { IRatio }\end{array}$ & . & . & $\cdot$ & $\checkmark$ & $\checkmark$ & $\checkmark$ & $\mathbf{x}$ & $\checkmark$ & $\checkmark$ & $\checkmark$ & $\checkmark$ & $\checkmark$ & $\checkmark$ & $\checkmark$ & $x$ & $x$ & $\mathrm{x}$ \\
\hline
\end{tabular}

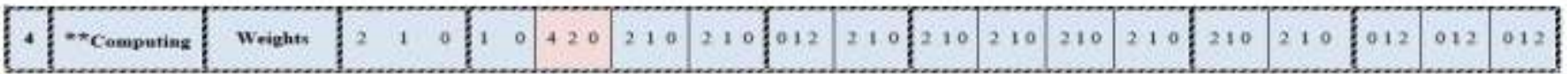

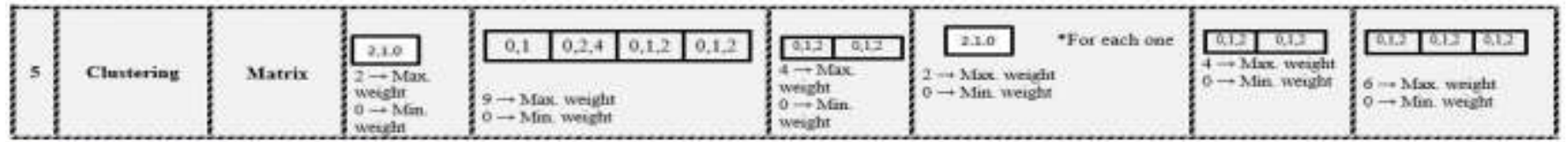

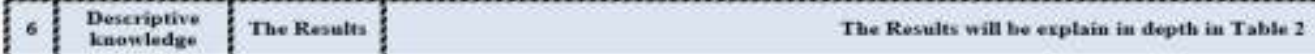




\section{Collect Data and Information based on Indicators}

The weighted results for each financial ratio in Index 1 were set in a one-dimension matrix. Referring to Iindex 4, then these values are summed to get one value per financial indicator. Using a division Hierarchical Clustering, the weight obtained from the matrix is classified into groups. Each weight has a different justification, which helps the user in making financial decisions. These weights clustering are presented in Table II. Example on applying a division Hierarchical Clustering on liquidity ratios shows how the FSD model acquires the weight for each equation as shown in Fig. 2.

In the same way, the division cluster is applied to debt, profitability, activity, and risk ratios and to the financial structured.

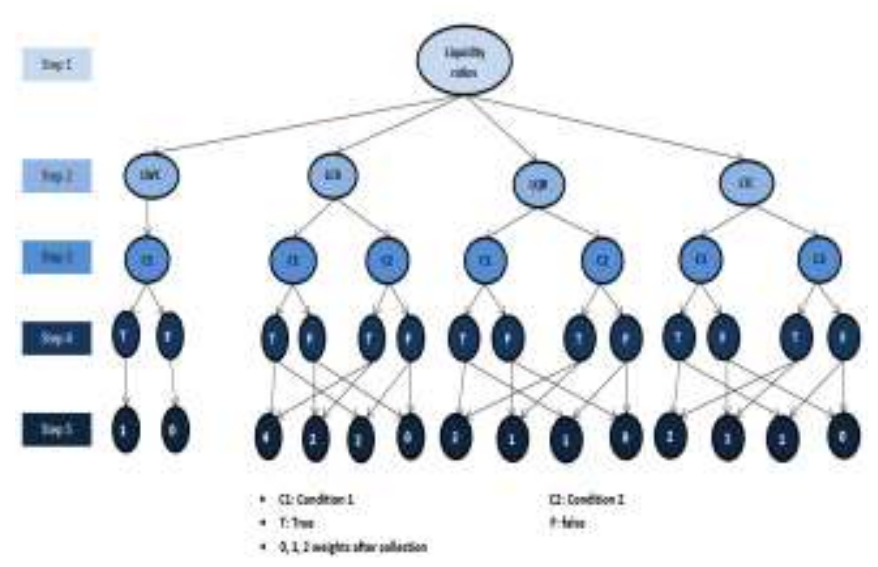

Fig. 1. Appling Division Clustering.

\section{DEVELOPMENT}

As there are different tools available for implementing a BI solution, we decided to use the Microsoft suite of BI tools, which facilitates a seamless integration of IT infrastructure. The various components on a Microsoft SQL Server supported our implementation of the BI solution such as:

- SQL Server Database Engine: This includes the Database Engine, storing, processing, and securing.

- Analysis Services: This includes the tools for creating and managing data mining applications.
- Reporting Services: This includes server and client components for creating, managing, and deploying reports.

- Power BI services: This includes the visualizing of final reports.

As shown in Table II, a condition will be applied on Profitability, Debt, and activity ratios due to the two different justifications at a specific weight. In other words, depending on the interruption of the conditions as below:

- Profitability at weight 1: This means one out of two KPIs conditions was fulfilled. It will have a justification, if the fulfilled condition was "If calculated ratio greater than or equal to the industry ratios?" And a different justification if this condition is not met.

- At Debt at weight 2: It has two different justification based on the result from each calculated ratio. If the results of preprocess data are not equal to zero in one of the calculated ratio's weights have a justification differ from if not.

- As the same as in debt weight at 2, the same at activity weight at 2 .

The biggest weight for each financial ratio differs from one to another, for example:

- Financial structure and profitability ratios (ROA, ROE, ROS, and ROI) highest weight is 2 , which represents $100 \%$ on the graph presentation for these ratios.

- Debt and Activity ratios highest weight is 4 , which represents $100 \%$ on the graph presentation for these ratios.

- By the same way the risk ratio highest weight is 6 and liquidity ratio's is 9 .

Two case studies will be used to illustrate the working mechanism of this model in detecting the initial financial stumble in SMEs. 
TABLE II. JUSTIFICATION FOR WeIGHTS Clusters AT FSD MODEL

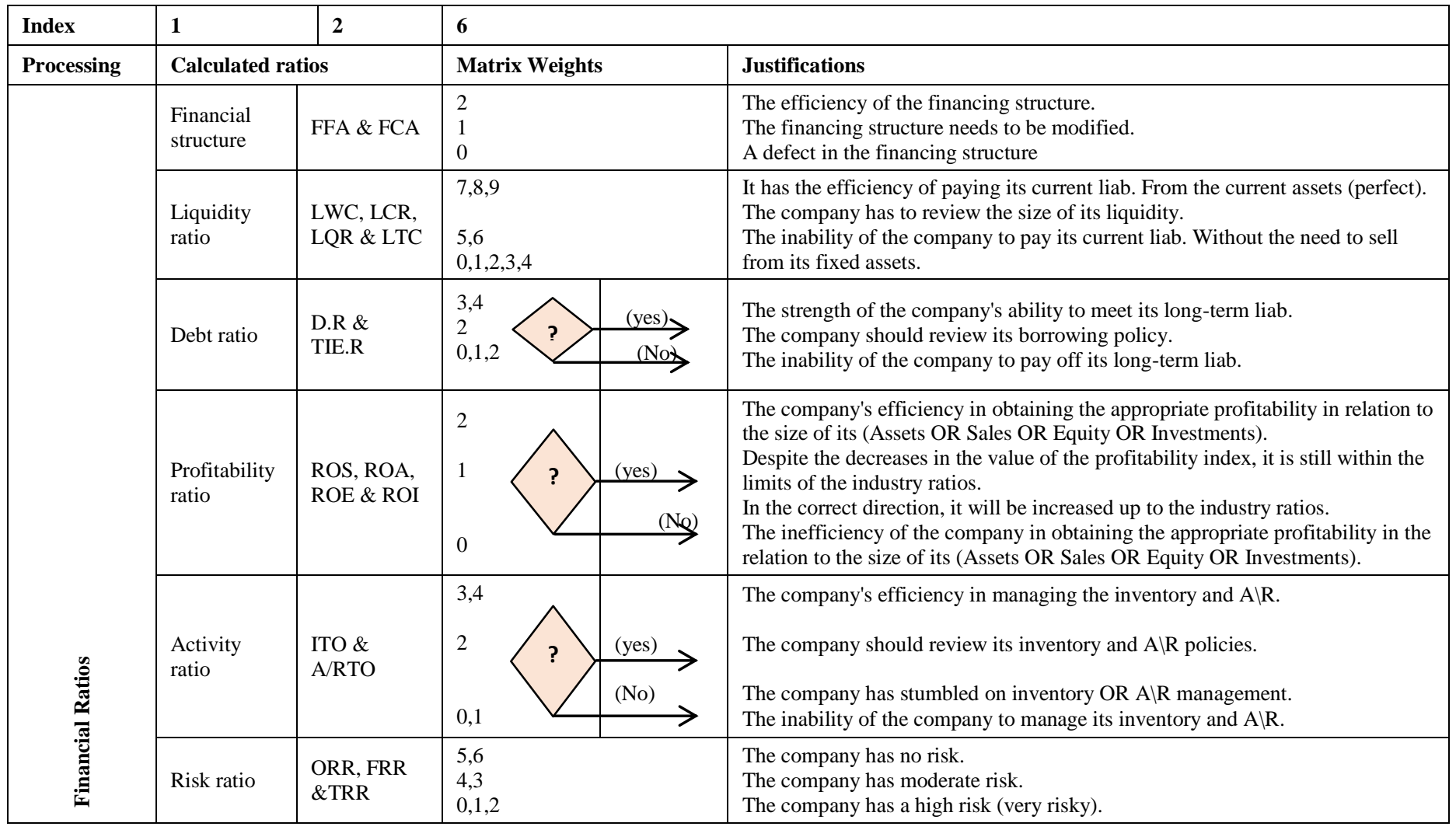

\section{EVALUATION}

\section{A. Case Study 1 (ABC Company)}

The financial statements of the company for two fiscal years are used to calculate the financial ratios needed in the FSD model according to Indexes 1 and 2 in Table I.

After Appling FSD Model on ABC Company, the model illustrates that referring to Table III:
1) At Index 2 FFA and FCA in the financial structure, the two conditions were fulfilled in Index 3, so referring to index 4 FFA and FCA had weighted with value 2 out of 2 which shows in Fig. $2100 \%$. So the model can illustrate that the Company has efficiency in its financial structure according to the justification of the resulted weight.

TABLE III. AFTER APPLIED FSD MODEL ON ABC COMPANY

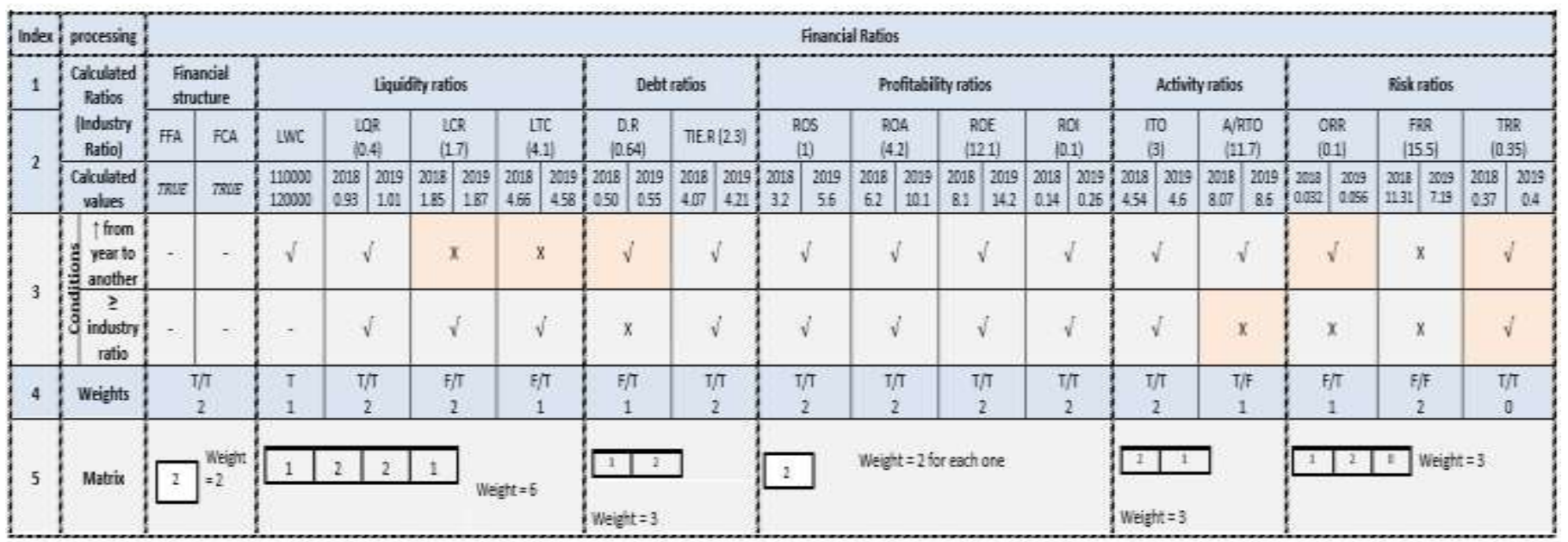


2) In profitability ratios (ROA, ROS, ROE, and ROI) the two conditions in Index 3 were fulfilled for each ratio. So it weighted in Index 5 to be 2 out of 2 which is shown in Fig. 2 $100 \%$, which is justified as it has efficiency in obtaining the appropriate profitability in relation to the size of its Assets, Sales, Equity, and Investments.

3) In the Liquidity Ratios, only 1 KPIs condition was fulfilled for LCR \& LTC referring to index 3 . So with referring to index 5 the total weights of this ratio have become 6 out of 9 which is shown in Fig. 2, 66.67\%, which is justified as The company has to review the size of its liquidity.

4) Inactivity ratios, the 2 KPIs conditions were fulfilled at ITO, and only 1 KPIs condition was fulfilled at AIRTO referring to Index 3 . So the activity ratios had weighted with value 3 out of 4 which is shown in Fig. 2, 75\%. This is justified as it has a strength of ability to meet its long-term liabilities and has efficiency in managing its inventory and AIR.

5) In risk ratios, the model illustrated that there is a moderated risk in this company. Because referring to Index 3 in ORR only 1 KPIs condition was fulfilled and in TRR there were no condition was meet. So Risk ratio was weighted to be 3 out of 6 which is shown in Fig. 2, 50\%.

Using Visualization, the overall view of $\mathrm{ABC}$ Company is followed in Fig. 2:

The graph illustrates that:

The company has efficiency in its financial structured, but it has to review the size of its liquidity. It has also the strength of ability to meet its long-term liabilities and efficiency in obtaining the appropriate profitability in relation to the size of its Assets, Sales, Equity, Investments, and in managing its inventory and A\R. Although the company's indicators all indicate that it is on right track, it has a moderated risk factor.

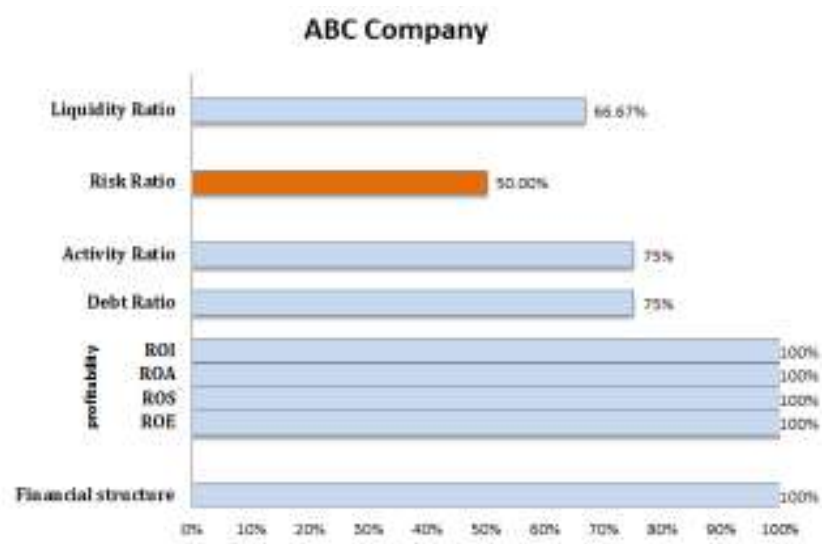

Fig. 2. ABC Company Visualization.

\section{B. Case Study 2 (XYZ Company)}

After appling FSD model on XYZ Company, the initial financial defects (stumbles) of the company which leads to being under shutdown are illustrated in Table IV as the following:

1) The company's financial structure needs to be modified, referring to Index 2 in Table IV, FFA $\leq$ long-term liab. + owner's equity but FCA > short-term liab. + Owner's equity, which means that was only one KPIs condition was fulfilled, thus it takes 1 out of 2 in the total weight, which is shown in Fig. 3 as 50\%.

2) In the liquidity ratio only one KPIs condition was fulfilled in LTC that weighted of value 1, there was no condition was meet in LCR, only LQR had the 2 conditions fulfilled as shown in Index 3. Referring to Index 5 the total concluded weight for this ratio was 3 out of 9 , which shows in Fig. 3 as $33.33 \%$. this means the inability of the company to pay its current liabilities without the need to sell from its fixed assets.

TABLE IV. AFTER APPLIED FSD MODEL ON XYZ COMPANY

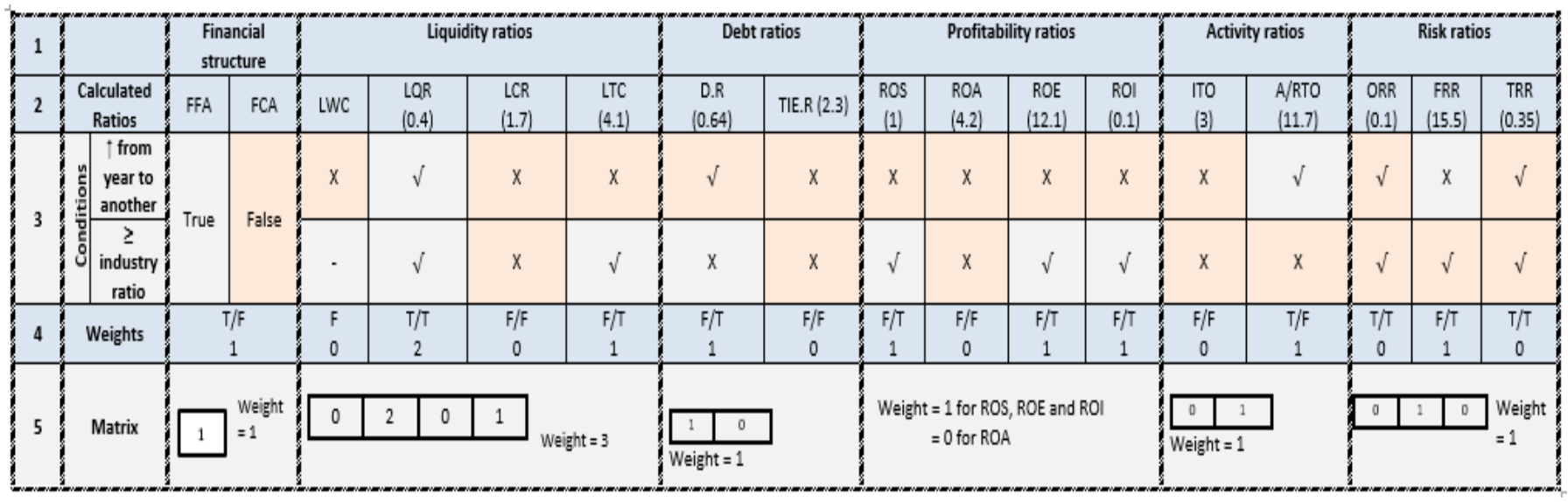


3) In debt ratios No conditions were meet in D.R, and only one condition was fulfilled in TIE.R. Referring to Index 5 , the concluded weight value was 1 out of 4 which shows in Fig. 3 as $25 \%$, which means the inability of the company to pay-off its long-term liabilities.

4) In profitability ratios, ROE, ROS, and ROI have only one KPIs condition that was fulfilled. Thus it takes 1 out of 2 in the total weight, which is shown in Fig. 3 as $50 \%$. Justified "Despite the decreasing in the value of the profitability index of ROE, ROS, and ROI, there are still within the limits of the industry ratios". In ROA no KPIs condition was meet, so the company has inefficiency in obtaining the appropriate profitability in the relation to the size of its Assets which is shown in Fig. 3 as $0 \%$.

5) Inactivity ratios, there was no KPIs condition was meet in ITO, and only one condition was met in AIRTO. Referring to Index 5, it takes 1 out of 3 in the total weight, which shows in Fig. 3 as $25 \%$. That means the inability of the company to manage its inventory and AlR.

6) In Risk Ratio It was justified as it has a high risk (very risky), because the ratio of ORR \& TRR increased from one year to another despite it must be decreased, and their values bigger than the industry ratios even though it must be smaller than or equal to industry ratio. That means there was no condition was meet in these ratios. And in FRR only one condition was fulfilled, referring to Index 5 the total weight equal to 1 out of 6 which is shown in Fig. 3 as 16.6\%.

Using Visualization, the overall view of ABC Company is followed in Fig. 3:

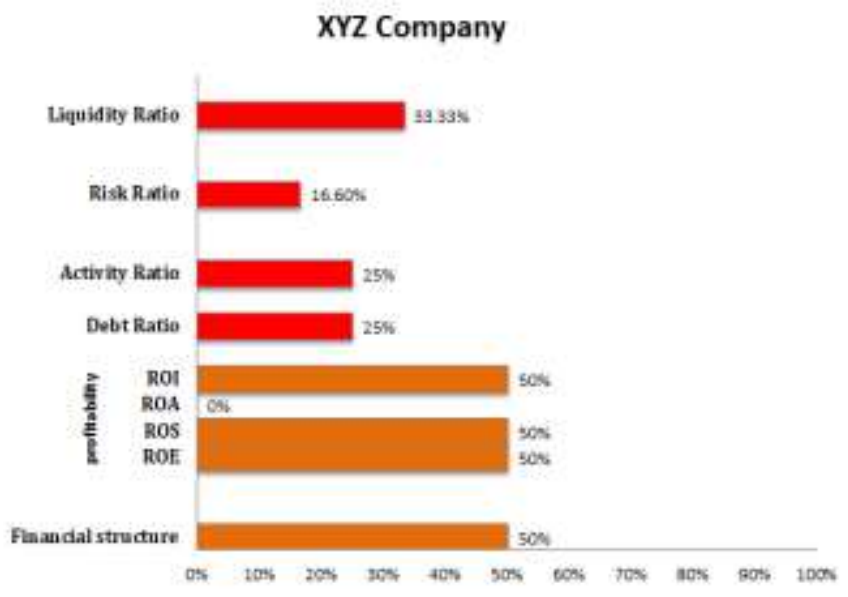

Fig. 3. XYZ Company Visualization.

Graph visualizes a summary of the resulted outcome of the model that illustrates:

The company's financial structure needs to be modified. And it has the inability to pay its current liabilities without the need to sell from its fixed assets and to pay off its long-term liabilities. Also, it had inefficiency in obtaining the appropriate profitability, cannot manage its inventory and AIR. Also, it has high risk (very risky).

\section{CONCLUSION}

Many challenges faced the researcher, from the difficulty in taking the permissions to make the interviews with the stockholders of SMEs, to the difficulty in getting the financial statements from the businesses. But all of these challenges have been successfully overcome.

Several limitations should be taken into account when evaluating the results of our research; we conducted empirical research in SMEs in Egypt only, on a relatively small sample, based on a cross-sectional approach additional sources of information could be used, such as cash flow statements and other financial indicators from official financial reports.

This work has been applied to eighteen cases studies on that model, the visualization results of the applied cases ensure that:

1) The ratio that weighted less than $50 \%$ has a defect/stumble on its structure or policies.

2) If more than three ratios out of six have a defect of less than $50 \%$ we can conclude that the company may be to be under the shutdown.

The user of financial background or SMEs stakeholder can indicate the stumbling reason of the company after seeing the visualization graph, knowing why was the company was under shutdown? Where was the defect?

The empirical FSD model proves its worth in identifying the initial stumble/defect in SMEs, using some financial ratios, by testing the concluded KPIs on the targeted data.

\section{REFERENCES}

[1] El-Said, H., Said, M., \&Zaki, C. (2013). What determines the access to finance of SMEs? Evidence from the Egyptian case. Economic Research Forum Working Paper (No. 752), The Economy Research Forum (ERF).

[2] Keskin, H., Senturk, C., Sungur, O., \& M. Kiris, H. (2010). The Importance of SMEs in Developing economies. International Symposium on Sustainable Development, (pp. 183-192). Sarajevo.

[3] Harraf, A., Wanasika, I., Tate, K. \&Talbott, K. 2015. Organizational Agility. Journal of Applied Business Research (JABR), 31, 675-686.

[4] R.G. Rathnam, Justin Johnsen \& H. Joseph Wen, (2005). Alignment of Business Strategy and It Strategy: A Case Study of a Fortune 50 Financial Services Company.

[5] Guarda, T., Santos, M., Pinto, F., Augusto, M. \& Silva, C. 2013. Business Intelligence as a Competitive Advantage for SMEs. International Journal of Trade, Economics \& Finance, 4, 187.

[6] Chai, J., Liu, J. N. K. A. \& Ngai, E. W. T. 2013. Application of decision-making techniques in supplier selection: A systematic review of literature. Expert Systems with Applications, 40, 3872-3885.

[7] Keh, H. T., Nguyen, T. T. M. \& Ng, H. P. 2007. The effects of entrepreneurial orientation and marketing information on the performance of SMEs. Journal of Business Venturing, 22, 592-611.

[8] Bandara W and Opsahl H. 2017. Developing Organization-wide BPM Capabilities in an SME: The Approaches Used, Challenges and Outcomes. Journal of Information Technology Teaching Cases. Vol 7 Issue 2.

[9] Llave, M. R. (2017). Business intelligence and analytics in small and medium-sized enterprises: A systematic literature review. Procedia Computer Science, 121, 194-205.

[10] H Suh, J Hillegersberg, J Choi, S Chung. 2013. Effects of strategic alignment on IS success: the mediation role of IS investment in Korea. Information Technology and Management, Vol 14Issue 1,7-27. 
[11] Pina, R. (2011), Report on Rustainability Reporting and Reporting Tools, Stellenbosch, Western Cape.

[12] Bosire, S. (2014), A Sustainability Reporting Framework for a Higher Education Institution, Nelson Mandela Metropolitan University, Summerstrand.

[13] Adelman, S., Moss, L.T. and Abai, M. (2005), Data Strategy, AddisonWesley, Boston, MA.

[14] Adeyelure, TS, Kalema, BM, Bwalya, KJ. Deployment factors for mobile business intelligence in developing countries small and medium enterprises. Afr J SciTechnolInnov Dev 2018; 10(6): 715-723.

[15] Broccardo, L, Culasso, F, Truant, E. Business Process management: an investigation in Italian SMEs. In: Ninth annual conference of the EuroMed Academy of Business: innovation, entrepreneurship and digital ecosystems, Warsaw, Poland, 14-16 September 2016, pp. 366376. Warsaw, Poland: EuroMed Press.

[16] Raj R, wong SHS and Beaumont AJ. (2016), business intelligence solution for an SME: a case study. Proceedings of the eighth international joint conference on knowledge discovery, knowledge engineering and knowledge management. vol.3, pp. 41-50.

[17] Raj R, Wong SHS and Beaumont AJ. Empowering SMEs to make better decisions with business intelligence: a case study. In: International joint conference on knowledge discovery, knowledge engineering, and knowledge management, Porto, Portugal, 9-11 November 2019, pp. 306-325. Cham: Springer.

[18] Gauzelin, S, Bentz, H. An examination of the impact of business intelligence systems on organizational decision making and performance: the case of France. J Intell Stud Bus 2017; 7(2): 40-50.

[19] Gudfinnsson K and Strand M. Challenges with BI adoption in SMEs. In: 2017 eighth international conference on information, intelligence, systems \& applications (IISA), Larnaca, Cyprus, 27-30 August 2017, pp. 1-6. USA: IEEE..

[20] Puklavec B, Oliveira T and Popovic ${ }^{\sim}$ A. Understanding the determinants of business intelligence system adoption stages: an empirical study of SMEs. IndManag Data Syst 2018; 118(1): 236-261.

[21] Kuechler, William and Vaishnavi, Vijay (2012) "A Framework for Theory Development in Design Science Research: Multiple Perspectives," Journal of the Association for Information Systems: Vol. 13, Iss. 6, Article 3.

[22] Hevner, A. (2007), "A three cycle view of design science research", Scandinavian Journal of Information Systems, Vol. 19 No. 2, pp. 1-6.

[23] Rossi, M., Kolte, A., Festa, G., Pawar, P. and Gunardi, A. (2019), Proceedings of the 12th EuroMed Conference 'Business Management Theories and Practices in a Dynamic Competitive Environment', Thessaloniki, Greece, 18-20 September, pp.1048-1058.

[24] Gibson, Charles H. (2013). Financial Statement Analysis. SouthWestern Cengage Learning, 13th Edition.

[25] Laitinen, E. K., (2018). Financial Reporting: Long-Term Change of Financial Ratios. American Journal of Industrial and Business Management 8(9), 1893-1927.

[26] AlviaHernaTertia, WaspodoTjiptoSubroto ,(2021). The Influence of the Covid-19 Pandemic on the Financial Performance of Construction SOEs Listed on the Indonesia Stock Exchange, Ekuitas: JurnalPendidikanEkonomi vol,9(1) · pp.137 - 145.

[27] Financial and statistical report on the actual data extracted from the financial statements of investment projects for the fiscal years 2017, 2018. (2018). General Authority for Investment \& Free Zones. https://www.investinegypt.gov. 